\title{
SOBRE O CONCEITO DE ARTE COMO EXPERIÊNCIA NO GRUPO DE ESTUDOS ESTÚDIO DE PINTURA APOTHEKE ${ }^{1}$
}

Fábio Wosniak²

\begin{abstract}
Resumo
Neste artigo apresento reflexões sobre o conceito de arte como experiência, fundamentação teórica amplamente investigada no Grupo de Estudos Estúdio de Pintura Apotheke. O Estúdio de Pintura Apotheke é um programa de extensão vinculado ao Grupo de pesquisa [Entre] Paisagens (CNPQ/UDESC). Neste texto, o objetivo é apresentar o referencial teórico no qual o Grupo desenvolve suas reflexões teórico-práticas articulando um saber que não dissocia teoria de prática.
\end{abstract}

Palavras Chaves : Arte como experiência, Estúdio de Pintura Apotheke, Arte Educação

\section{ABOUT THE CONCEPT OF ART AS EXPERIENCE IN THE STUDY GROUP APOTHEKE PAINTING STUDIO}

\begin{abstract}
In this article I present reflections on the concept of art as experience, theoretical foundation extensively investigated in the Study Group of Apotheke Painting Studio. The Apotheke Painting Studio is an extension program linked to the Research Group [Between] Landscapes (CNPQ / UDESC). In this text, the objective is to present the theoretical reference in which the Group develops its theoretical-practical reflections articulating a knowledge that does not dissociate theory of practice.
\end{abstract}

Keywords: Art as Experience, Apotheke Painting Studio, Art Education

\footnotetext{
${ }^{1}$ O Programa de extensão 'Estúdio de pintura Apotheke', coordenado pela Professora Dr.. Lampert, oferece oficinas, mini cursos, palestras, aulas abertas e residências artísticas, que envolvam a temática da pintura, para estudantes de Graduação, Pós-Graduação e comunidade acadêmica (e fora da UDESC), que tenham interesse na área de Artes Visuais, especificamente na linguagem pictórica. Desta forma, oportuniza um espaço para conhecimento e aprofundamento sobre determinadas técnicas e processo pictórico, bem como, conversas e trocas de saberes com artistas que tenham conhecimento e notoriedade no meio artístico.

A palavra APOTHEKE tem origem grega no substantivo apotheke, que designava armazéns do porto de Atenas na Grécia Clássica; Também de origem germânica, indica a origem da palavra botica, boticário ou farmácia. A escolha por esta nomenclatura decorre da percepção da botica como lugar de laboratório, de um labor experimental, o que se aproxima da proposta do grupo que traz em sua fundamentação teórica a referência de John Dewey. Neste sentido, aponta-se para Arte como Experiência, como eixo de interação entre prática e teoria, não fazendo distinção entre o saber artístico e um saber intelectual, considerando o espaço/tempo Universitário onde estamos inseridos.

${ }^{2}$ Doutorando em Artes Visuais na Linha de Pesquisa de Ensino das Artes Visuais sob a orientação da Profa. Dra. Jociele Lampert- PPGAVUDESC; (UDESC) - fwosniak@gmail.com
}

Criar Educação, Criciúma, v. 7, no1, jan/jul 2018.- PPGE - UNESC 


\section{Introdução}

Arte como Experiência foi o último livro escrito por John Dewey, publicado nos Estados Unidos em 1934. No Brasil sua publicação aconteceu no ano de 2010 pela Editora Martins Fontes. Os escritos do livro foram resultado de conferências que o filósofo proferiu na Universidade de Harvard sobre o tema Filosofia da Arte.

É relevante reconhecer que a Filosofia da Arte como experiência pretende recolocar a Arte em um campo democrático, não apenas oferecendo ao espectador estímulos compensatórios, transitórios e agradáveis. Seu projeto é o de exercitar o pensamento, em que as obras auxiliam na compreensão das nossas práticas sociais, abrindo novas possibilidades de nos compreendermos no mundo.

A Filosofia da Arte defendida por Dewey, mesmo tendo sido elaborada em 1934, ressoa reflexões relevantes para o cenário da Arte Contemporânea, principalmente para o campo da Arte Educação, tendo em vista que uma de suas ideias expoentes é a de que "a arte é o locus paradigmático dos valores, e a criação e o prazer advindo da arte são o protótipo dos objetivos dignos da condição humana" (Kaplan, 2010, p. 10).

A singularidade da Filosofia deweyiana é a incessante crítica que o autor faz aos sistemas das artes maiores (Belas-Artes). O filósofo coloca essas totalizações na província da alienação, como também coloca em dúvida as divisões irredutíveis entre os produtos das artes maiores e a Cultura Popular.

O conhecimento acentuado pelo exercício da Arte no âmbito da experiência desempenha um papel crucial nos significados acumulados pela experiência cultural. A percepção, compreendida na filosofia da Arte como experiência tem o poder de reorganizar a consciência, de tornar a visão autônoma, questionando as "interpretações autorizadas" da obra de Arte. Este é o conhecimento democrático e libertador, quando qualquer pessoa que aprende e ressignifica através da sua própria experiência o saber estético. É pensar em nutrir esforços para dar sentido às experiências, insistindo na capacidade da imaginação, percepção, sentimento, como fontes promotoras de conhecimento.

Nessa noção, compreender a Arte como experiência significa entender que a Arte não se separa da Vida. Como experiência, a Arte é uma parte da vida. E toda experiência artística é legitimada por uma experiência estética, que é amparada por Criar Educação, Criciúma, v. 7, no1, jan/jul 2018.- PPGE - UNESC 
elementos práticos e cognitivos.

É exclusivamente essa concepção da Arte como experiência que o Grupo de Estudos Estúdio de Pintura Apotheke elege para encontrar caminhos que revelem uma nova perspectiva acerca da pesquisa em Artes Visuais, como também, na articulação entre Artes Visuais e Educação.

\section{Filosofia da Arte em John Dewey}

A filosofia pragmática de Dewey não se refere exclusivamente à ação, mas o que o autor deflagra nesta corrente é uma teoria filosófica do pensamento e do sentimento, onde o pensamento norteia a ação e o sentimento reconhece as consumações dispostas por ela - uma conscientização unificada pelo sentir e agir. John Dewey foi o filósofo norte-americano mais relevante da primeira metade do século XX. Seu pensamento baseava-se principalmente na convicção moral de que "democracia é liberdade" - uma sociedade democrática prepara todos os indivíduos, de maneira igualitária, assegurando seus benefícios, por meio de variadas formas da vida associada.

A prerrogativa mais importante para compreender o conceito de experiência cunhado por Dewey é a de recusar as verdades absolutas e as dicotomias. Dewey defende um princípio de continuidade em toda sua filosofia, onde essa continuidade confere uma unidade, que nada se aproxima de imutabilidade. Para Dewey, unidade implica flexibilidade e continuidade de interações (AMARAL, 2007).

Amaral (2007, p.39) explica que a unidade na teoria deweyiana trata

(...) de uma unidade apoiada na flexibilidade das interações e aqui poderíamos perfeitamente acrescentar a palavra "sociais, sem que com isso estivéssemos prejudicando a clareza do pensamento do autor, mas, pelo contrário, reforçando-a. trata-se ainda de uma unidade que pressupõe a diversidade e poderíamos igualmente acrescentar, dos "espíritos", sem incorrer em qualquer distorção do seu pensamento.

A unidade presente na filosofia de John Dewey une a relação do indivíduo ao meio, aquela entre o homem e o mundo. Compreender o conceito de unidade presente na filosofia deweyiana torna-se fundamental para apreender o conceito de Arte como experiência e de Estética. Dewey não abandona as qualidades holísticas, Criar Educação, Criciúma, v. 7, no1, jan/jul 2018.- PPGE - UNESC 
historicistas e organicistas na sua filosofia. O autor busca as "origens estéticas nas necessidades naturais, na constituição e nas atividades do organismo vivo" (SHUSTERMAN, 1988, p. 233). A estética pragmática de John Dewey, segundo Shusterman (1988, p. 231), "ocupa a posição ideal para reorientar e revigorar a filosofia da arte contemporânea". Nesta perspectiva, "as oposições entre mente e corpo, alma e matéria, espírito e carne originam-se todas, fundamentalmente, no medo do que a vida pode trazer" (DEWEY, 2010, p. 89).

Assim, já vemos esboçada uma contraposição com as teorias dualistas e especificistas, ou seja, com aquelas teorias estéticas onde os valores principais eram os de praticar distinções entre Arte e Vida. Dewey considera a criatura viva em toda a sua totalidade, cabendo uma filosofia que compreenda a articulação do homem com o seu meio, onde a experiência é a "chave-mestra" para revelar a vitalidade unificada da experiência estética entre o homem e a Arte.

A noção de Arte presente na obra de John Dewey reside na relação que a criatura viva tem com seu ambiente, o naturalismo deweyiano torna-se necessidade para toda obra de Arte. Neste sentido, a função da Arte é unificar a vitalidade consciente presente na vida humana, pois as obras de Artes qualificadas não geram experiências estéticas especializadas - elas aprimoram a percepção, a comunicação, originando fontes de energia e inspiração. A experiência estética é a responsável em ampliar e aprimorar todas as inquietações humanas. Shusterman (1998, p. 238) explica que a função da Arte para Dewey:

(...) não residem em algum fim particular, especializado, mas sim em satisfazer a criatura viva de maneira global, servindo a fins variados e, acima de tudo, aumentando a nossa experiência imediata, que nos revigora e vitaliza, assim, a realizar qualquer fim que busquemos.

Para John Dewey, a arte deveria se situar ao lado das coisas da experiência comum da vida, ou seja, inserida em um contexto diretamente humano, ao contrário de estarem relegadas exclusivamente aos museus ou galerias, compartimentalizadas em teorias que distanciam as experiências estéticas da vida cotidiana, ou seja, do prazer pessoal que, segundo o autor, está próximo às coisas da natureza, como o ar, o solo, a luz, as flores. Seriam desses lugares que brotariam as coisas esteticamente admiráveis. (DEWEY, 2010).

Criar Educação, Criciúma, v. 7, no1, jan/jul 2018.- PPGE - UNESC 
A filosofia da Arte defendida por Dewey reestabelece a união entre as formas mais sofisticadas do artístico com os sentimentos mais ordinários da vida humana. $A$ constante interação entre sujeito e ambiente, juntamente com os resultados dessa relação, será o que constituirá uma experiência. Na relação entre a Arte e a Estética, o filósofo afirma que o trabalho poético, desenvolvido em uma perspectiva da filosofia da Arte como experiência, seria o clímax da sofisticação entre a união dos saberes - afetivo, intelectual e prático (DEWEY, 2002). Na perspectiva do filósofo, as Artes oferecem vitalidade e aprofundam o conhecimento das experiências acumuladas, porque

[...] toda arte envolve órgãos físicos, como o olho e a mão, o ouvido e a voz $\mathrm{e}$, no entanto, ela ultrapassa as meras competências técnicas que estes órgãos exigem. Ela envolve uma ideia, um pensamento, uma interpretação espiritual das coisas e, no entanto, apesar disto é mais do que qualquer uma destas ideias por si só. Consiste numa união entre o pensamento e o instrumento de expressão. (DEWEY, 2002, p. 76).

É justamente na integração entre o pensamento e o instrumento de expressão que se pode esboçar uma ideia do que o autor nos comunica a respeito da experiência estética. A experiência para Dewey é um processo do viver que relaciona-se de maneira intensa e contínua entre o mundo e o sujeito. Dessa relação brotam conflitos, resistências, impressões. Destes elementos, por sua vez, emergem as experiências, envoltas em ideias e emoções.

A Arte "é uma variedade da experiência, e não uma entidade em si (...) a experiência é uma questão da interação do produto com o eu" (Dewey, 2010, p.558). O encontro da interação implica o movimento de todo o organismo envolvido no acontecimento da experiência estético-artística, e este percurso é o "acontecer da criação". Para que ele seja reconhecido e perpasse pela experiência estética, o que acontece antes da criação é um estado peculiar na apreciação do artista, que mais tarde é apresentado como uma ideia poética. Por sua vez, a ideia poética fará emergir as distinções - a singularidade que, por mais vagante e indefinida que seja, as partes definidas deste percurso apresentarão suas qualidades imediatamente experimentadas quando a percepção ganhar potência na consciência.

Sob esse foco, a obra de arte e sua compreensão manifesta, em toda a sua totalidade e qualidade estética, é o que a distingue das outras formas de Criar Educação, Criciúma, v. 7, no1, jan/jul 2018.- PPGE - UNESC 
conhecimento. A obra de arte é mais do que o mistério do gosto ou da expressão da sensibilidade, a arte e o processo artístico buscam uma forma própria de integração do homem com o mundo. No conhecimento artístico, as coisas não são parcelarizadas - a experiência é globalizante, integradora, promotora de experienciações e experimentações que evoluem para experiências estéticas, quando o planejamento é minuciosamente articulado para tal acontecimento. A objetividade a ser alcançada nesse projeto de conhecimento a partir da arte como experiência atravessa a objetividade simplesmente pelo encerramento do que está sendo proposto a conhecer. O objetivo se funde com o subjetivo, onde o sujeito que conhece integra-se através do seu plano de conhecimento com o objeto, pois ele, que aprende sob essa perspectiva, é capaz de criar a ordem, ou a maneira com que vai aprender. Tendo em vista que ele surge integrado no seio do próprio objeto, ele não está observando o mundo de fora, estamos todos imersos no mesmo mundo e dentro dele. É assim que a arte nasce, desse encontro do eu em sua completude com o mundo.

\section{Arte como experiência}

A Arte para Dewey é experiência, e esta experiência é parte integradora da vida, que deve ser concebida pela filosofia estética como um momento de materialização formada no interior da experiência consumada. Como experiência a Arte é fragmento de vida, intencionada em um fluxo contínuo dos acontecimentos significantes.

A estética é uma característica intrínseca à experiência, residindo na profundidade e no desfecho dos encontros com as coisas da vida. A Arte, neste aspecto, é um modo de fazer tudo isso acontecer.

Percorrendo os caminhos da Arte como Experiência, Dewey declara que é no movimento de cada arte e de cada obra que habitam as razões, as relações que cada criatura viva estabelece com seu meio. Dewey reconstrói uma Filosofia Estética em que o papel da Arte não é o de negação das necessidades naturais e orgânicas dos sujeitos, em oposição à noção de que a Arte eleva nossas sensações a planos etéreos. Ao contrário disso, a Arte apresenta de forma satisfatória e integrada as dimensões corporais e intelectuais da nossa existência. Sendo a Arte uma realização do organismo 
humano, em constante estado de lutas em um mundo de coisas, ela deverá servir a estes organismos uma vitalidade unificadora (DEWEY, 2010).

$\mathrm{Na}$ concepção deweyiana de arte como experiência, esta manifestação estética humana propicia e mantém vivo o nosso poder de sentir o mundo, através da ideia de unificação que a experiência com a arte produz. Nesta noção reside um corpo vivo, nos revigorando e revitalizando.

No texto Cultura e Indústria na Educação (2001), o autor menciona que a Arte não é uma produção ou um comportamento externo; a Arte é uma forma, um modo de satisfazer e realizar de maneira mais aprimorada a nossa percepção das coisas. É ao mesmo tempo um regozijo do ato de fazer com o de perceber - um exercício inteligente entre o pensamento, a ação e o controle da Natureza. "Arte, em uma palavra, é a indústria extraordinariamente consciente de seu próprio significado - adequadamente consciente, emocional e intelectualmente" (DEWEY, 2001, p. 31).

Assim, se a Arte é integração entre o fazer/pensar/sentir, e não algo externo, sua apreciação também não se encontra externa ao seu próprio fim em si, nem tampouco sua apreciação é garantida ancorada em outras formas de saber. Existe na Arte uma autonomia. Esta autonomia lhe confere um valor, algo que lhe é próprio, como fins em si, e não como meio ou instrumento para outros propósitos de outras práticas. Esta singularidade que permite a Arte uma autonomia, certamente é a experiência estética,

[...] Em uma experiência nitidamente estética, algumas características atenuadas em outras experiências se revelam dominantes; as subordinaras tornam-se controladas - a saber, as características em virtude das quais a experiência é uma experiência integrada e completa por si só (DEWEY, 2010, p. 139).

Este poder que Dewey atribui à experiência estética concede à Filosofia uma condição original para se compreender o campo da Arte. Como afirma Barbosa (2001),

[...] a originalidade de Dewey consiste em fixar a velha discussão sobre artes maiores e artes menores dentro do contexto da experiência humana em geral e, particularmente, do processo educacional, em vez de deter-se no significado de cada uma como um circuito fechado (p. 146).

Com a noção de experiência estética, Dewey retira exclusivamente da prática artística historicamente estabelecida o exclusivismo da Arte como sendo apenas para 
alguns, e a recoloca, em primeiro lugar, junto aos processos do viver. "[...] toda experiência é resultado da interação entre a criatura viva e algum aspecto do mundo em que ela vive" (DEWEY, 2010, p. 122).

Este aspecto da experiência estética, não limitada ao domínio da prática artística historicamente estabelecida, é justificada por Dewey, porque primeiramente esta experiência existe na apreciação da natureza, situando principalmente o corpo como parte essencial da Natureza.

Dewey não estava apenas rompendo com toda uma tradição filosófica tradicional e dualista. Ele também rompia com toda a rotina e automatismo empregado à forma de pensar a Arte. Isso não significa simplesmente acabar com a separação entre as BelasArtes e a Cultura Popular, mas significa expandir nossa compreensão sobre o que o domínio da Arte inclui. Para Dewey, a experiência estética pode ser encontrada tanto no útil como nas belas-artes (DEWEY, 2010) .

Enclausurar a experiência estética no âmbito das belas-artes significa restringir a Arte apenas à tradição de uma História da Arte apreendida pelas Belas-Artes e sua vanguarda elitista. Esta concepção da Arte e sua experiência resignada à tradição das Belas-Artes, no ponto de vista da Filosofia da Arte como experiência, é redutora e ressoa uma concepção da sociedade moderna, que divide o trabalho prático da experiência estética, sendo que o trabalho prático é compreendido como algo desagradável e a experiência estética como fonte de alegria e prazer.

Esta divisão que separa a Arte da sua experiência estética e, principalmente, que a isola em teorias compartimentalizadas, distanciando-a da vida e dos processos normais do viver, afetam, como afirma Dewey (2010), a prática da vida, afastando os sujeitos dos ingredientes necessários da felicidade, da inteligência.

Cultivar uma articulação com este saber, da Arte integrada aos processos do viver, exige realçar a concepção do fazer estético-artístico e de obra de arte presente no interior dos estudos no Grupo de Estudos Estúdio de Pintura Apotheke. O fazer estéticoartístico é compreendido como um tempo/espaço de reinventação, ao mesmo tempo que desterritorializa e reterritorializa, cria novas aberturas estético-políticas, possibilitando um modo de vida que seja nascente para onde a vida tenha mais fôlego para "recomeçar".

Esse fôlego permite o recomeço. Contudo, o recomeço que os membros do Grupo são impulsionados a experienciar é aquele que nos coloca, de forma consciente do Criar Educação, Criciúma, v. 7, no1, jan/jul 2018.- PPGE - UNESC 
nosso inacabamento como humanos, que nos incita a viver em um mundo com os Outros, com o conhecimento e com nossos não saberes. No tocante à formação estética, o que esta noção implica é, justamente, o íntimo contato com a experiência na via do estético-artístico, em que valores e julgamentos são constantemente convocados a se refazerem. O fazer prático incluso nas metodologias de pesquisa não estão direcionadas exclusivamente para o Outro, mas importa ao sujeito que a produziu. Este fazer, além de estar em um diálogo permanente com as experiências anteriores, é também o produto da experiência presente, pois “a função moral da própria arte é eliminar o preconceito, retirar os antolhos que impedem os olhos de ver, rasgar os véus decorrentes do hábito e do costume, aprimorar a capacidade de perceber (DEWEY, 2010, p. 548).

Dessa forma, é o juízo crítico que é convocado. Este juízo, nesta maneira de fazer/sentir/pensar Artes Visuais, brota diretamente da experiência e do contato com a prática estético-artística, tomando as obras de artistas como os maiores referências para os estudos. O trabalho estético-prático-reflexivo tem função de reeducar a percepção do mundo. É uma forma refinada de aprender a ver e a ouvir, distanciado de preconceitos, como afirma Dewey na citação acima.

Assim como a concepção estética é ressignificada, o conceito de obra de arte é compreendido no âmbito do tempo vivido, em que tempo e criação se sobrepõem um ao outro, estão em um tempo/espaço que delatam o mundo sem excluir suas fissuras e lacunas.

É, portanto, neste sentido que a filosofia da Arte como experiência e a experiência estética, são compreendidas a cada avanço dos estudos deweyianos no Grupo de Estudos Estúdio de Pintura Apotheke.

A experiência estética é uma sequência de consumações, e nunca cessações. Neste tipo de experiência residem fluxos constantes, lugares de repouso, unidade, e o seu desfecho é atingido por um movimento ordeiro e organizado. O material vivenciado, ao mesmo tempo em que é marcado pelas percepções, é transformado pelas experiências anteriores. "A conclusão é uma consumação, e não uma cessação. Esta experiência carrega um caráter individualizador e autossuficiente.” (DEWEY, 2010, p. 110)

A experiência estética é uma espiral, seu fluxo contínuo unifica a percepção entre Criar Educação, Criciúma, v. 7, no1, jan/jul 2018.- PPGE - UNESC 
o que é feito e o que é suportável; cria conexões com experiências anteriores - uma observação constante entre o que existiu, existe e existirá, o processo é vivenciado conscientemente. A ansiedade e as frustações, que fazem parte da vida cotidiana e estão presentes no processo criativo, não são impeditivas para que a inteligência organize a consumação da experiência pulsante; discernimento entre ações e desejos, não há dicotomias, fragmentações entre inteligência e sensibilidade. Tudo se relaciona, tudo está junto, é o próprio processo do viver unificado ao ambiente tomando consciência de si - esse conjunto consciente propicia ao sujeito uma experiência estética. O estético, na filosofia da arte de John Dewey, não é um fator externo e que se "lança" para a experiência. Tampouco está relacionado ao luxo, ou é idealizado por qualquer corrente de pensamento transcendental. Para o autor, "o estético (...) é o desenvolvimento esclarecido e intensificado de traços que pertencem à toda experiência normalmente completa (...) estético refere-se à experiência como apreciação, percepção e deleite" (DEWEY, 2010, p. 125-127).

O estético presente na experiência e que faz desta uma experiência estética, possui uma forma distinta de operação. O estético torna a experiência consciente através da classificação do que é percebido - a consciência do conhecimento. Esse movimento de relações está sempre unificado, incorporado com a apreensão reflexiva de experiências anteriores. O material singular da percepção estética é o equilíbrio e a proporção. Estes materiais surgem da experiência, num primeiro momento das ideias, que proporcionam ao pensamento um carácter estético. A experiência se torna predominantemente estética quando seu desenvolvimento é controlado, ou seja, quando aquilo que é feito transmite a ideia que está sendo executada. A ordem e a realização existem e sinalizam o percurso da ideia, mesmo que assinalem o desvio e a ruptura (DEWEY, 2010).

Dewey afirma que "a arte, em sua forma, une a mesma relação entre o agir e o sofrer, entre a energia de saída e a de entrada, que faz com que uma experiência seja uma experiência" (DEWEY, 2010, p. 128). Como o artístico está relacionado ao ato de produção e o estético ao ato de prazer e percepção, uma obra acontece em sua completude quando o artista, ao trabalhar, assume essas duas atitudes transformando-a em uma só, ou seja, numa atitude artístico-estética.

Portanto, Dewey desafia toda a tradição filosófica acerca do conceito de estética. 
O autor coloca o estético, assim como as Artes, nas origens da existência humana. Ele revela que a experiência estética deve estar nos processos normais do viver, nas coisas cotidianas da vida. Segundo Dewey (2010, p. 72), "se as obras de arte fossem colocadas em um contexto diretamente humano na estima popular, teriam um atrativo muito maior do que podem ter quando as teorias compartimentalizadas da arte ganham aceitação geral". O autor afirma ainda que "a genuína arte se desenvolve a partir do trabalho do artesão" (Dewey, 2002, p. 76), defendendo que o grande desenvolvimento proporcionado por um trabalho estético-artístico está associado à vida cotidiana, nas coisas simples (DEWEY, 2002).

É desse lugar, que os pressupostos filosóficos dewyiano falam de uma Filosofia da Arte como experiência. Consciente desse processo, a experiência possibilita ao indivíduo uma reorganização que o coloca em contato com outras formas de apreender a vida. Por isso, a experiência estética é inerente à consumação, e nunca a uma conclusão. Entende-se por consumação "um certo nutrir-se" constantemente da experiência que no seu fluxo-refluxo-repouso avança para novas reformulações, onde outras percepções irão envolver esses atos e ideias de pensamento. O pensar também ocorre em fluxos, esses fluxos são fases carregadas de afetividade; não são evoluções, mas variações móveis (DEWEY, 2010).

\section{Viver o saber}

A experiência estética da qual nos fala Dewey transcreve-se também em dimensões pedagógicas, pois perpassa a escolha, a seleção e o repertório dos membros do Grupo de Estudos. Toda Arte, que busca novas maneiras de pensar o mundo, diferente dos sistemas tradicionais e hegemônicos do conhecimento, "precisa educar seu público em novos modos de percepção. Assim, a arte é essencialmente educativa, não somente em seu aspecto instrumental, mas através do consumatório e do instrumental fundidos na experiência." (BARBOSA, 2001, p. 147)

As obras de Arte refletem a potência política, discursiva e pedagógica de um tempo/espaço em que o artista está situado, e pode também situar o espectador dependendo do modo como ele incorpora essa imagem com suas experiências anteriores. $\mathrm{Na}$ obra de arte, é possível observar os elementos visuais presentes no Criar Educação, Criciúma, v. 7, no1, jan/jul 2018.- PPGE - UNESC 
universo dos artistas. Neste sentido, "ver" envolve algo além do mero reconhecimento de objetos e coisas. "Ver de fato", para além do reconhecimento, envolve reconstruir a consciência e torná-la viva. Como afirma Dewey, "esse ato de ver envolve (...) a cooperação de todas as ideias acumuladas que possam servir para completar a nova imagem em formação" (Dewey, 2010, p.135).

A obra de arte, apreendida em uma perspectiva da filosofia da Arte como experiência, convoca espectador e artista a "ver de novo" ou "ver o novo". Este olhar, que são resultados de experiências, afloram no indivíduo uma configuração do mundo, ou seja, um conhecimento acerca das coisas do mundo. O olhar, agora inquiridor, produz no sujeito um movimento no organismo em sua inteireza - a impulsão. A impulsão, diferente do impulso (que é um movimento especializado e particular), necessita do reconhecimento dinâmico que o meio produz. Ela evoca e revela a necessidade do organismo em dependência do Eu em relação ao seu contexto, onde a junção das experiências não são simples justaposições de fatos velhos e novos, a recriação do olhar no qual a impulsão atual ganha forma e solidez, converte-se em ato de expressão (DEWEY, 2010). O ato de expressão não é mera descarga do organismo, mas sim transformação consciente, ou seja, ato do qual o indivíduo aprendeu a perceber a relação entre o fazer e o vivenciar. Esse ato de expressão, que constitui uma obra de arte, "é uma construção no tempo, e não uma emissão instantânea" (DEWEY, 2010, p. 153).

A impulsão que leva à expressão mistura-se com as energias orgânicas e ambientais, onde os nós desta tecelagem vão se desfazendo, dando espaço às condições objetivas, pois a impulsão e o ato expressivo ocorrem distante das regras rígidas, eles surgem com a opacidade do pensamento, da insatisfação, do inacabamento - aparecem como enigmas. A partir das inquietações dessa impulsão, o ato expressivo vai sendo recriado, assegurando que a expressão artística seja reelaborada. Sendo assim, a expressão é o esclarecimento do conjunto evocado pela impulsão, é o valor do ato expresso, é a matéria da experiência.

É relevante salientar que este valor do ato expressivo, a matéria prima da experiência que Dewey revela em sua obra, tem grande aproximação com a organização das emoções e a objetividade. Porém, organização e objetividade, para o filósofo, não são "coisas simples" de serem alcançadas pelo organismo que, fragmentado pelo Criar Educação, Criciúma, v. 7, no1, jan/jul 2018.- PPGE - UNESC 
ambiente e imerso nas teorias reducionistas explora, na maioria das vezes, experiências incipientes.

A organização, segundo Dewey "é colocar as coisas em contato umas com as outras de forma que estas funcionem com facilidade, flexibilidade e de forma ampla" (DEWEY, 2002, p. 60). Neste fluxo, o ato expressivo se diferencia de todas as outras relações com as experiências incipientes, ganhando um caráter único, singular - ou seja, estético. A experiência estética não possui uma única fonte de elementos particulares. Ela se diferencia pela integração de todos os elementos da experiência ordinária (SHUSTERMAN, 1998).

A teoria dewyiana da Arte como experiência toma o argumento da aprendizagem em si mesma. Nesse conjunto da aprendizagem, o saber a consolidação do pensamento e da percepção são identificados como os fatores decisivos para que ela ocorra. Isso muitas vezes torna a filosofia da Arte como experiência distante dos discursos acadêmicos e escolares, tendo em vista o caráter totalmente utilitário e prático que estas instituições estão inseridas.

A Filosofia de Dewey distancia-se das distinções classificatórias e consolidadoras do pensamento, que automatizam e padronizam a nossa percepção do mundo, onde essas acabam por estabelecer rotinas fixas e padrões de concepções. A filosofia da Arte como experiência aumenta nossos valores com a natureza. Segundo Amaral (2007), natureza no conceito deweyiano não é apenas o conjunto das coisas, mas

\begin{abstract}
(...) as nossas relações, a mudança como permanência, a espontaneidade como necessidade, o regular como o novo, a morte como nascimento, os elementos permanentes como os acontecimentos em mudança, não esgota todo o significado da palavra dentro do pensamento deweyiano (...) na verdade, esse é o resultado para quem, como Dewey, pretendeu substituir todos os dualismos pela ideia de continuidade entre natureza e experiência. Fruto desse propósito, ele naturalizou o homem, colocando-o no seio da natureza como mais um elemento dentre outros. No entanto, ao reconhecer as extraordinárias diferenças que marcam as realizações humanas, foi obrigado a dilatar o mundo da natureza a tal ponto que não estabeleceu simplesmente a continuidade entre os dois mundos, o da natureza e o da experiência, mas os fundiu a ambos. (AMARAL, 2007, p. 53).
\end{abstract}

Sendo assim, tudo é natural na filosofia de Dewey, pois a natureza impera. Mas a natureza não está só - para que ela aconteça, precisa ser experimentada pelos seres humanos. É nesse sentido que a apreciação ganha destaque importante na obra do Criar Educação, Criciúma, v. 7, no1, jan/jul 2018.- PPGE - UNESC 
nosso filósofo. Apreciar alguma coisa é revelar como essa coisa mostra-se na nossa experiência, ou seja, é dizer da nossa prática, como o Ser é percebido - ser é ser experimentado (AMARAL, 2007).

Por isso, o saber instrumental defendido na teoria da Arte como experiência reconhece que o objetivo presente na teoria deweyiana não pretende encontrar uma verdade absoluta ou um saber sobre si mesmo, ou ainda um domínio sobre a natureza. O objetivo, a que se refere Dewey, é de enriquecer as experiências e experimentações de um valor, controlando as ações que são realizadas nesse empreendimento de descobertas e propiciando a liberdade. Para Dewey, essa forma de saber, aproximada de um saber que segue as experiências, só se torna possível com a experiência estética, pois a Ciência, para o filósofo, é subordinada à Arte (SHUSTERMAN, 1998).

Shusterman (1998) explica que para Dewey o mundo da arte não compõe um conhecimento estético arbitrário e independente, mas sim um saber que está articulado ao mundo real e aparelhado nas condições socioeconômicas e políticas. Nas palavras do autor (1998): Dewey compreendeu que não apenas os conceitos de arte e estética sobre
os quais teorizamos, mas também nossos próprios conceitos sobre teoria e
filosofia, são estruturados e condicionados pelas práticas sociais e
institucionais que informam nossas vidas e pensamentos. Portanto, são
também condicionados pelas contingências e lutas da história que, de certa
forma, moldam essas instituições e práticas estruturadoras.
(SHUSTERMAN, 1998, p. 254).

Diante disso, vale observar que Dewey fundamenta toda a teoria na capacidade democrática dos seres humanos. Afinal, a experiência humana na Filosofia da Arte como experiência encontra ancoragem na capacidade de julgar e agir dos seres humanos com inteligência, desde que sejam propiciadas as condições apropriadas.

Ainda no que tange à capacidade dos seres humanos numa filosofia da Arte como experiência, vale ressaltar que Dewey considera a Arte a partir de uma dinâmica e desenvolvimento experimental. A partir desse movimento é que a experiência estética é criada e percebida. O valor da Arte, para o filósofo, não reside no conceito museológico da arte. Nesta concepção, a Arte exige estímulos e tensões, assim como novidades revolucionárias, nutrindo-se do constante conflito da quebra da ordem. Por isso, Dewey ressalta os movimentos fluxo-refluxo-repouso.

Criar Educação, Criciúma, v. 7, no1, jan/jul 2018.- PPGE - UNESC 
Trazer a Arte para o centro da vida cotidiana, como requer Dewey, é acreditar que esse cotidiano possa ser poetizado. O lugar potencial para que essas transformações ocorram seria, sem dúvida, os espaços educativos. Manter um projeto educativo voltado às questões estético-artísticas propiciaria que os novos apreciadores de Artes fossem realmente apreciadores capazes de transformarem as experiências incipientes em experiências estéticas.

\section{Referências}

AMARAL, Maria Nazaré de C. Pacheco. Dewey: Filosofia e experiência Democrática. São Paulo: Perspectiva, 2007.

BARBOSA, Ana Mae. John Dewey e o Ensino da Arte no Brasil. São Paulo: Cortez, 2001.

DEWEY, John. Arte como experiência. São Paulo: Martins Fontes, 2010.

2002.

. A Escola e a Sociedade a Criança e o Currículo. Lisboa: Relógio D’água, . Indústria Cultural e Educação. In: BARBOSA, Ana Mae. John Dewey e o Ensino da Arte no Brasil. São Paulo: Cortez, 2001.

KAPLAN, Abraham. Introdução. In: DEWEY, John. Arte como experiência. São Paulo: Martins Fontes, 2010.

SHUSTERMAN, Richard. Vivendo a arte: o pensamento pragmatista e a estética popular. São Paulo: Editora 34, 1998.

Recebido em dezembro 2017

Aprovado em fevereiro 2018 